\title{
The Lutzomyia longipalpis complex: a brief natural history of aggregation-sex pheromone communication
}

\author{
Carolina N. Spiegel ${ }^{1,3 *}$, Denise B. dos Santos Dias ${ }^{2,3}$, Alejandra S. Araki ${ }^{3}$, James G. C. Hamilton 4 , \\ Reginaldo P. Brazil ${ }^{5}$ and Théresa M. Jones ${ }^{6}$
}

\begin{abstract}
In this paper we review the natural history of pheromone communication and the current diversity of aggregation-sex pheromones in the sand fly Lutzomyia longipalpis. This species complex is the main vector of Leishmania infantum, the agent of visceral leishmaniasis in the Americas. The identification of variation in pheromone chemotypes combined with molecular and sound analyses have all contributed to our understanding of the extent of divergence among cryptic members of this complex. The importance of chemical signals as pre-mating barriers and drivers of speciation is discussed. Moreover, the importance of aggregation-sex pheromones as sexually selected signals is highlighted with evidence from the literature suggesting their potential role in species and mate recognition as well as mate assessment. The distinct evolutionary forces possibly involved are briefly reviewed and discussed in the context of this intriguing insect.
\end{abstract}

Keywords: Lutzomyia longipalpis, Sex pheromone, Aggregation pheromone, Species complex, Evolution, Sand flies

\section{Background}

\section{A brief history of invertebrate sex pheromones}

The first identification and published account of a sex pheromone (bombykol) was from the female silk moth, Bombyx mori in 1959 [1]. Karlson \& Luscher [2] formally defined this new class of biologically active substances as pheromones (from the Greek "pherein", to transfer and "hormōn", to excite) and suggested a broad-based definition of pheromones as "substances that are secreted by an animal to the outside and cause a specific reaction in a receiving individual of the same species, e.g., a release of certain behavior or a determination of physiologic development." [3]. Today there are more than 1,600 molecules described as sex pheromones spanning the majority of animal orders [4]; however the insects are by far the most prevalent taxon in the chemical world and exploit olfaction as their primary communication channel [5]. The definition

\footnotetext{
* Correspondence: carolina.spiegel@gmail.com; carolinaspiegel@id.uff.br ${ }^{1}$ Departamento de Biologia Celular e Molecular, Instituto de Biologia, Universidade Federal Fluminense, Outeiro de São João Batista s/n, Valonguinho, Centro, Niterói 24.020-150, RJ, Brazil

${ }^{3}$ Laboratório de Biologia Molecular de Insetos, Instituto Oswaldo Cruz, FIOCRUZ, Rio de Janeiro 21040-360, RJ, Brazil

Full list of author information is available at the end of the article
}

of a sex pheromone remains somewhat contentious. Broadly defined, it is any chemical that is emitted by one sex that elicits a response in the opposite sex; however, this definition maybe too restrictive. Johansson \& Jones (2007) expanded the original definition, defining a sex pheromone as "any substance that is released by an individual, either directly from a specialized structure or that arises through changes in body chemistry, and that promotes subsequent variation in the sexual behaviour of individuals within the same species to the benefit of the releasing individual." [6]. It is this broader definition of sex pheromones that we adopt here, however we note that in cases where a sex pheromone has a dual function, for example, to promote mating aggregations it may be necessary to further subclassify the chemical; in this instance as an aggregation-sex pheromone, sensu [7].

Over the past 57 years, our functional and mechanistic understanding of sex pheromones and pheromone communication has been transformed [5, 6, 8, 9]. Advancements are, in part, due to the increased sensitivity of detection and technologies surrounding accurate measurement. To place it into context the successful isolation of bombykol required 500,000 female moths; while today 
such analyses can be achieved with just a few or even single moths [10]. Precise measurement of the quantity and quality of chemicals emitted by single individuals has revealed considerable individual variation in both the composition and release rates of pheromones [6].

The majority of pheromones, regardless of their function, are comprised of more than one active component and they are typically species- and sometimes populationspecific. To operate effectively and convey specific information, a pheromone is required to provide a message that permits accurate discrimination. This is particularly pertinent if there are multiple sympatric species using pheromones as their primary mode of communication. The specificity of the message can be achieved in a multitude of ways including variation in overall composition, the presence and composition of stereoisomers $[11,12]$ or the ratio of specific components all of which may lead to qualitative and quantitative differences in the signal emitted $[5,13,14]$. Even subtle changes in the pheromone blend (the specific ratios of chemicals within a pheromone) [15] or partitioning of communication channels through temporal or seasonal differences in pheromone production and emission as well as shifts in circadian activity [16-18] may result in individuals being unable to detect one another $[9,18,19]$ and thus lead to speciation. Other factors such as the interaction with host produced volatile chemicals and preferences for particular habitats could also contribute to serve as mechanisms that lead to the avoidance of cross attraction between closely related heterospecifics that exist in sympatry [18].

Theoretical and empirical analyses of the evolution of sex pheromones suggest that pheromone blends evolve in one of two distinct and context-dependent ways [5]. The first proposes a gradual process of incremental changes in the pheromone blend, such as the loss or gain of single components, or variation in their relative proportions over evolutionary time. This hypothesis predicts that chemical signals are: highly conserved, are maintained through stabilizing selection, and are largely resistant to change. This mode of evolution results in phylogenetic conservatism, with closely related species having similar, or even identical, pheromone compositions. The alternate view suggests that pheromones, far from being conserved and stable, evolve rapidly via large saltational shifts [5]. Such saltational shifts generate a phenotype that either differs greatly or is completely different from the antecedent and may result in sibling species having highly dissimilar pheromones reducing the likelihood of interspecific responses. However, even when the pheromones of related species exhibit considerable differences in chemical composition, many compounds of pheromone blend have structural similarities, indicating that they share biosynthetic pathways [20].

As a signal, pheromones may be complex and multifaceted and they can have multiple meanings depending on their context. Accordingly, sex pheromones have evolved and are maintained for a range of different functions such as species recognition, mate recognition and mate assessment $[6,21]$. In species recognition, pheromones are used to discriminate between hetero- and con-specifics (members of the same species), thus interspecific competition for communication channels and selection for pre-mating reproductive isolation are the primary driving evolutionary forces. Pheromones involved in mate recognition indicate sex and reproductive status, and can advertise female receptivity for example. The environment is the predominant factor affecting the evolution of this kind of signal. Finally, mate assessment pheromones advertise the identity of the sender and its potential quality as a mate and, assuming this signal is honest (see below), they are predicted to be highly variable between individuals [6]. Theoretical contributions on the evolution of pheromones and empirical studies of pheromone-mediated mate choice also support the notion that sex pheromones can act as indicators of mate quality and are indeed used in individual mate assessment [21]. To be adaptive, mate assessment pheromones are predicted to correlate either directly or indirectly with traits such as condition, fertility, female reproductive status, age, parasite load, nutritional status, maturity, immunocompetence $[6,21]$ or inbreeding status [22]. These are mutually non-exclusive levels of mate choice and may be viewed as a continuum ranging from sexual isolation between species to individual mate assessment.

Arguably, to best understand the importance or role of chemical divergence in the process of speciation it is necessary to study groups, such as species complexes where gene exchange in nature is still occurring [6]. Here, we review the studies that contribute to the history of aggregation-sex pheromones within the phlebotomine sand fly, Lutzomyia longipalpis (Lutz \& Neiva) species complex. We discuss the evolutionary forces that may be acting to maintain the integrity of the pheromone and highlight where future studies and investigations are required to better facilitate our understanding of the underlying mechanisms maintaining the observed variation in their aggregation-sex pheromone.

\section{The sand fly Lutzomyia longipalpis \\ Epidemiological importance}

Visceral leishmaniasis (VL) is a vector-borne parasitic disease of significant medical importance because it can be lethal, it is difficult to treat and there is currently no vaccine [23]. It is estimated that $200,000-400,000$ new cases of VL occur worldwide annually and over $90 \%$ of new cases occur in just six countries: Bangladesh, Brazil, Ethiopia, India, South Sudan and Sudan. The death rate due to this disease is estimated to be 20,000 to 40,000 per year [24]. The sand fly L. longipalpis (Diptera: Psychodidae) 
is the main vector of American visceral leishmaniasis (AVL). Females, but not males are haematophagous, requiring and feeding on vertebrates' blood to complete their gonotrophic cycle leading to the transmission of Leishmania (Leishmania) infantum (Nicolle) the etiological agent of the disease AVL [25-27].

Lutzomyia longipalpis has a wide geographical distribution in the Americas, occurring from Mexico to Argentina, and is found in a range of different habitats and diverse ecological conditions [25, 28]. Over the past 30 years, a new scenario has emerged as L. longipalpis has extended its natural range and adapted to domiciliary habitats in urban areas throughout Brazil, resulting in an increase in the incidence of both canine and human visceral leishmaniasis [26, 29]. Given its epidemiological significance a thorough understanding of the ecology and life history of the Lutzomyia species complex is critical. Advancement in this area has been pioneered by studies on pheromonal communication; indeed, such studies provide pivotal evidence for the existence of the $L$. longipalpis species complex.

\section{The Lutzomyia longipalpis species complex}

The first suggestion that $L$. longipalpis may be a sibling species complex came from the observed polymorphism in the number of abdominal spots on males [30]. All $L$. longipalpis males exhibit pale spots on their abdominal tergites; however, some populations have a single pair on the fourth tergite (one spot phenotype, named 1S), while others have two pairs on the third and fourth tergites (two spot phenotype, named 2S). In a few natural populations, there are also phenotypes in which the size of the tergal spot on the third segment shows considerable variation; the so-called intermediate forms (INS) (Fig. 1).

Scanning electron microscopy analysis of the tergites demonstrated the presence of numerous cuticular papules with central pores only on tergites with pale spots [31], suggesting that these might be sites of pheromone release. Further analysis revealed that the spot formation commences in the pupal phase and that, in the tergites where the aggregation-sex pheromone disseminating structures were located, the macrotrichia were absent perhaps facilitating pheromone dispersion [32]. Lane \& Bernardes [33] used transmission electron microscopy of the tissue beneath the pale spots and showed a group of large columnar cells with an end apparatus connected to the exterior via a small cuticular duct, typical of gland cells. These were similar to the Lutzomyia male "odoriferous gland" described by Barth in 1961 [34], who first suggested that these glands were involved in stimulating the female prior to copulation. Unequivocal evidence for the role of these glandular areas in the production of sex pheromones in $L$. longipalpis was provided by Ward et al. (1989), who impregnated filter paper disks with whole tergal gland
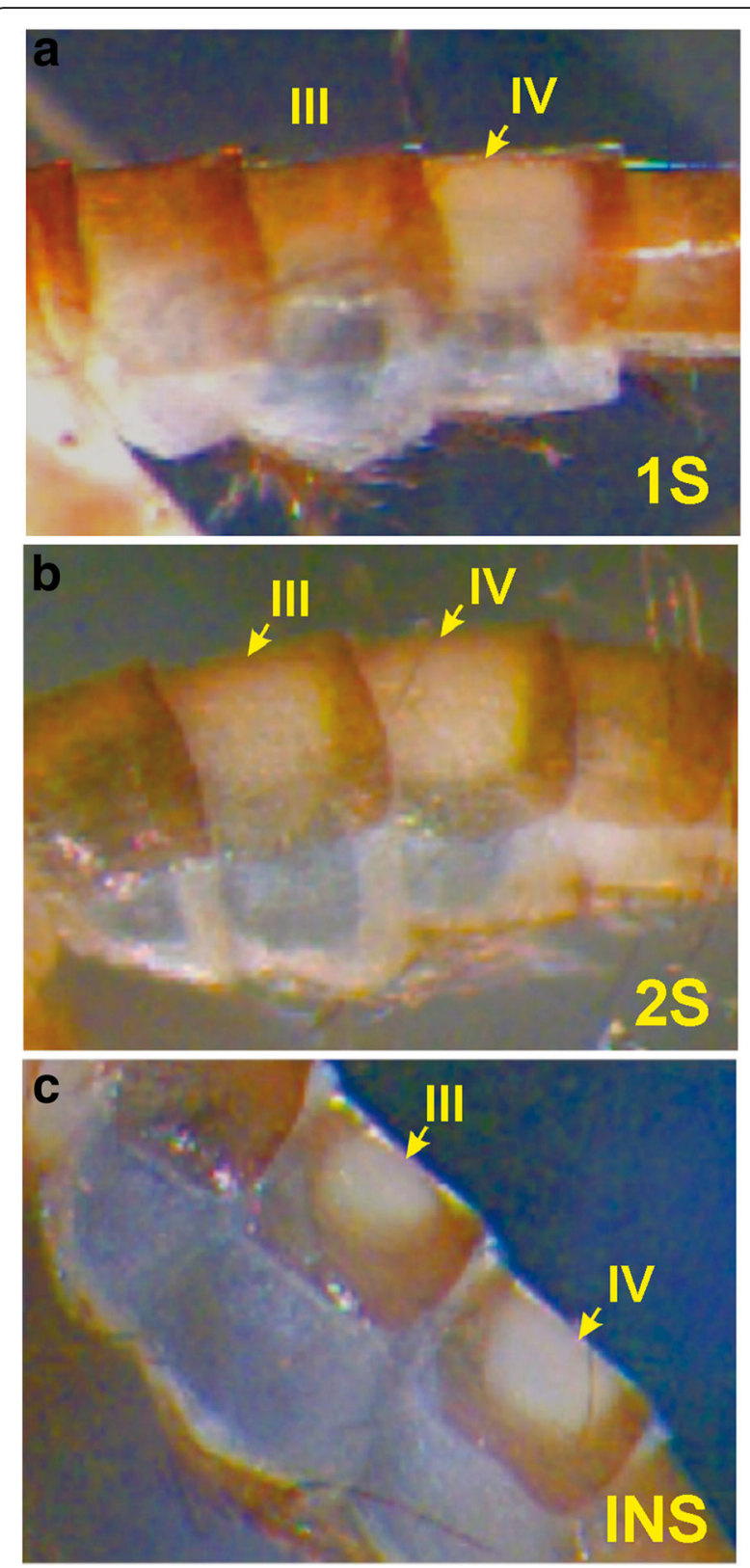

Fig. 1 Morphological variation in the abdominal tergal pale spot patterns in males of Lutzomyia. longipalpis. a Single pale spot on the fourth abdominal tergite (phenotype named one spot phenotype, 1S). $\mathbf{b}$ Two pale spots on the third and fourth abdominal tergites (phenotype named two spot phenotypes, 2S). c Intermediate forms with one whole spot on the fourth abdominal tergite and a half spot on the third tergite (phenotype named intermediate form phenotype, INS). Yellow arrows indicate the pale spot

extracts and subsequently demonstrated that females were attracted over distances of up to $60 \mathrm{~cm}$ [35].

Crossing experiments between sympatric and allopatric Brazilian populations of $L$. longipalpis with dissimilar pale spots patterns suggested some degree of reproductive isolation. However, there are instances of populations with 
the same phenotype that exhibit reproductive isolation and populations with different phenotypes that do not [36-38]. The relationship between the number of pale spots and reproductive isolation was clarified when gland extracts were analyzed using coupled gas chromatography mass spectrometry $[39,40]$. These analyses provided the first conclusive proof that male semiochemicals varied between different populations. Specifically, males were described as producing either a "farnesene/homofarnesene-like" molecule $\left(\mathrm{C}_{16} \mathrm{H}_{26}\right)$ or "diterpenoid-like" molecule $\left(\mathrm{C}_{20} \mathrm{H}_{32}\right)$. The reproductive compatibility of these populations correlated with the type of terpenoid compounds present was not associated with the spot phenotype [37-39], insects could share the same number of pale spots but the main component of the pheromone could vary. However, the reproductive incompatibility [37] between different populations was not fully explained by the presence of only 2 chemotypes.

Laboratory assays showed that the main component of an extract of the tergal spots was responsible for most of female's attraction and the minor components only marginally enhanced the attraction of the major component [41]. This initial behavioral analysis was carried out for the Jacobina (Bahia State, Brazil) population of L. longipalpis where the main component makes up $90 \%$ of the compounds found in the tergal gland extract. Based on the analysis of the main terpene component of the tergal gland extract, four distinct chemotypes can now be recognized in the $L$. longipalpis complex: chemotype 1 or (S)-9-methylgermacrene-B (9MGB) found for example, in several Brazilian States such as Minas Gerais, Piauí, Rio de Janeiro and Sao Paulo, as well as in other countries such as Argentina, Colombia, Paraguay, Honduras and Venezuela, chemotype 2 or $(1 S, 3 S, 7 R)$-3-methyl$\alpha$-himachalene $(3 \mathrm{M} \alpha \mathrm{H})$ in Jacobina (Bahia State) also found in L. pseudolongipalpis (Venezuela), chemotype 3 or cembrene-1 (CEMB-1) in Sobral 2S (Ceará State), Santarém (Pará State), Estrela de Alagoas $1 \mathrm{~S}$ and $2 \mathrm{~S}$ (Alagoas State), Costa del Sol (Alagoas State), Pancas (Espírito Santo State) and Jaíba 2S (Minas Gerais State), and chemotype 4 or cembrene-2 (CEMB-2) in Jaíba 1S (Minas Gerais State) [42-49]. Potentially, a fifth chemotype has been identified based on variation in the amount of specific terpenes present, as well as morphological differences: chemotype 5 (or 9MGB+) found in Sobral 1S, Sobral INS (Ceará State) and Montes Claros (Minas Gerais State) [46]. Currently, we consider chemotype 5 to be analogous to chemotype 1 , based only on the main component of the pheromone. However, sex pheromone specificity may depend on a range of factors such as differences in chain length, position of double bonds, stereo configuration or variation in the ratios of different components and thus understanding the significance of quantitative and qualitative variation in total terpenes is essential. Further work is required to confirm the epidemiological and evolutionary appropriateness of collapsing chemotype 5 into chemotype 1 ; however such studies are logistically challenging [46]. A map of the distribution of currently identified chemotypes within the L. longipalpis complex in the Americas (as well as some related species) are presented in Fig. 2 and Table 1. Notable is the fact that chemotype 1 (9MGB) was also identified in Lutzomyia cruzi (Mangabeira, 1938) [50], a sibling species that may turn out to be a part of the $L$. longipalpis complex [51]. The possibility that they are isomers has not been investigated by more refined analyses (Hamilton JG, Brazil R., Personal communication, 2015).

The best evidence for the existence of a L. longipalpis complex comes from observations of species coexisting in sympatry. Hamilton's et al. [46] comprehensive analysis of individual males of three different spot phenotypes (1S, $2 \mathrm{~S}$ and INS) from Sobral suggests that there are probably two sympatric chemotypes (3 and 5) corroborating previous findings [36, 52]. Mating-crosses between individuals from Lapinha Cave (9MGB, chemotype1) and Jacobina (3M $\alpha \mathrm{H}$, chemotype 2) yielded male offspring with both $9 \mathrm{MGB}$ and $3 \mathrm{M \alpha H}$ (Hamilton \& Rebollar-Tellez, unpublished). The absence of chemical hybrids of the 9MGB and CEMB-1 chemotypes in the individually analysed male samples from Sobral suggests that those two chemotypes are reproductively isolated. Crossing experiments carried out between the two Sobral chemotypes indicate both copulatory and pre-mating isolation [37]. In simple laboratory choice experiments individual Jacobina population females were attracted only to the conspecific pheromone and Sobral 2S females given a choice showed a preference for conspecific male pheromone, however they also responded to Jacobina male pheromone [53]. In contrast, field studies that used traps baited with pheromone from two different pheromone chemotypes (either 9MGB from Araçatuba, Sao Paulo State or CEMB-1 from Marajo, Para State) found that both male and female sand flies were significantly more attracted to their conspecific pheromone chemotype compared to the heterospecific chemotype. Combined these data provide strong support for the argument that the aggregation-sex pheromones act as an important pre-mating isolation barrier and may have diversified through selection operating within the L. longipalpis complex speciation [54].

Two general conclusions can be drawn from these studies: first, the spot phenotype cannot be used as a reliable marker to identify different species (although there are coincidental exceptions, e.g. in Sobral); secondly, the terpene profile of allopatric populations may be qualitatively the same as sympatric populations (e.g. CEMB-1 producing populations from Estrela de Alagoas, Sol da 


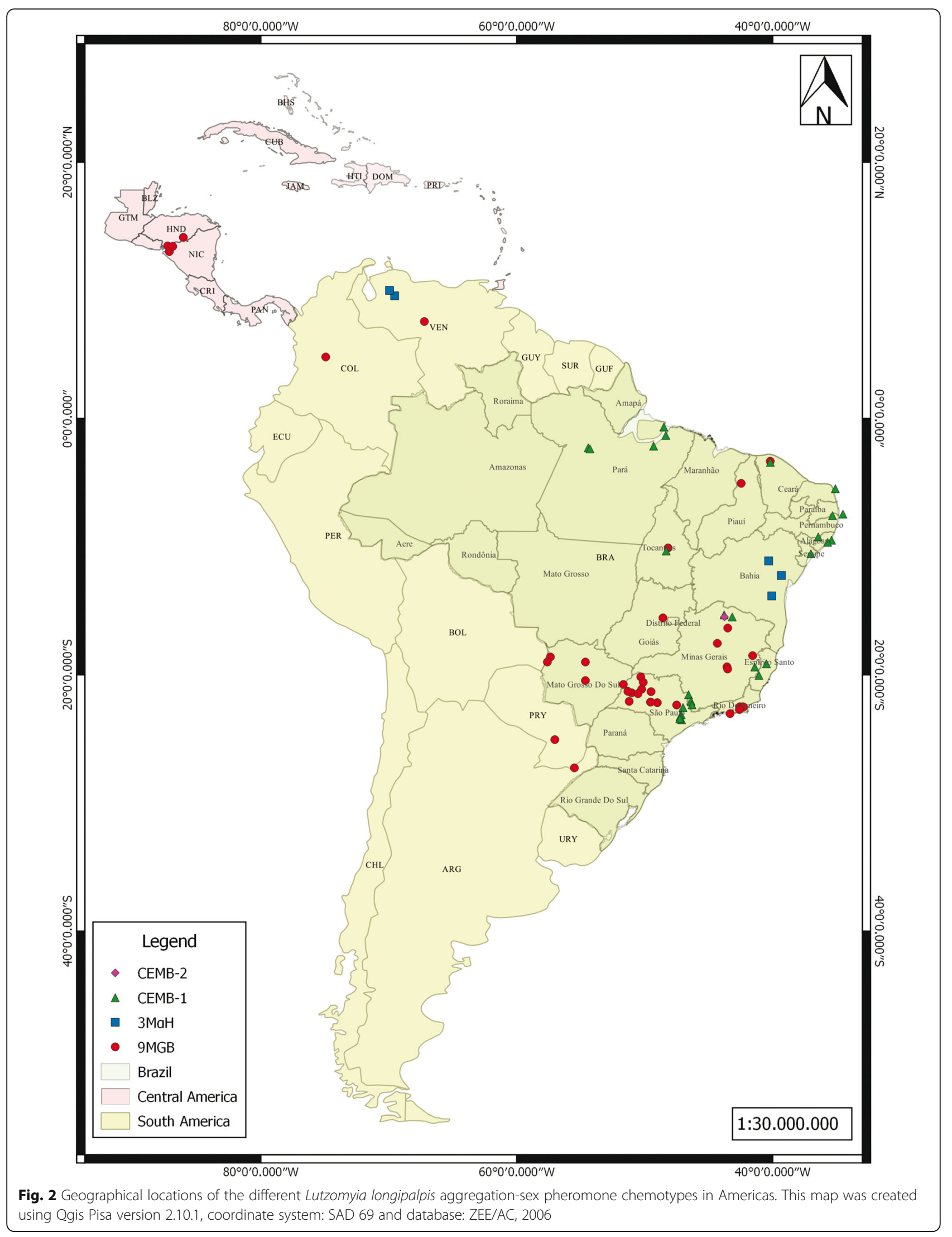


Table 1 Distribution of the different chemotypes described in America

\begin{tabular}{|c|c|c|c|c|c|c|}
\hline Chemotype & Pheromone & Species & Location & State & Country & Reference \\
\hline \multirow[t]{40}{*}{1} & $9 M G B$ & L. cruzi & El Carmen & & $\mathrm{BO}$ & $\begin{array}{l}\text { Hamilton \& Brazil (Personal } \\
\text { communication, 2015) }\end{array}$ \\
\hline & $9 M G B$ & L. cruzi & Corumbá & Mato Grosso do Sul & $B R$ & {$[47,50]$} \\
\hline & $9 M G B$ & L. cruzi & Ladário & Mato Grosso do Sul & $\mathrm{BR}$ & {$[47]$} \\
\hline & $9 M G B$ & L. longipalpis & Guayabita & Aragua & VE & {$[47]$} \\
\hline & $9 M G B$ & L. longipalpis & Vila Elisa & Asunción & PA & [114] \\
\hline & $9 M G B$ & L. longipalpis & Sobral & Ceará & $B R$ & {$[47]$} \\
\hline & $9 M G B$ & L. longipalpis & Orocuina & Choluteca & $\mathrm{HO}$ & [43] \\
\hline & $9 M G B$ & L. longipalpis & Pavana & Choluteca & $\mathrm{HO}$ & {$[43]$} \\
\hline & $9 M G B$ & L. longipalpis & San Juan Bautista & Choluteca & $\mathrm{HO}$ & [43] \\
\hline & $9 M G B$ & L. longipalpis & Tololar & Choluteca & $\mathrm{HO}$ & {$[43]$} \\
\hline & $9 M G B$ & L. longipalpis & Pirenópolis & Goias & $\mathrm{BR}$ & $\begin{array}{l}\text { Hamilton \& Brazil (Personal } \\
\text { communication, 2015) }\end{array}$ \\
\hline & $9 M G B$ & L. longipalpis & El Layero & Guárico & VE & {$[47]$} \\
\hline & $9 M G B$ & L. longipalpis & São Luís & Maranhão & $B R$ & $\begin{array}{l}\text { Hamilton \& Brazil (Personal } \\
\text { communication, 2015) }\end{array}$ \\
\hline & $9 M G B$ & L. longipalpis & 3 lagoas & Mato Grosso do Sul & $B R$ & $\begin{array}{l}\text { Hamilton \& Brazil (Personal } \\
\text { communication, 2015) }\end{array}$ \\
\hline & $9 M G B$ & L. longipalpis & Campo Grande & Mato Grosso do Sul & $\mathrm{BR}$ & [29] \\
\hline & $9 M G B$ & L. longipalpis & Belo Horizonte & Minas Gerais & $\mathrm{BR}$ & [51] \\
\hline & $9 M G B$ & L. longipalpis & Governador Valadares & Minas Gerais & $B R$ & $\begin{array}{l}\text { Hamilton \& Brazil (Personal } \\
\text { communication, 2015) }\end{array}$ \\
\hline & $9 M G B$ & L. longipalpis & Lapinha Cave & Minas Gerais & $\mathrm{BR}$ & {$[42,46,47]$} \\
\hline & $9 M G B$ & L. longipalpis & Montes Claros & Minas Gerais & $\mathrm{BR}$ & {$[46]$} \\
\hline & $9 M G B$ & L. longipalpis & Lassance & Minas Gerais & $B R$ & [51] \\
\hline & $9 M G B$ & L. longipalpis & Posadas & Misiones & $A R$ & {$[115]$} \\
\hline & $9 M G B$ & L. longipalpis & Teresina & Piauí & $B R$ & {$[48]$} \\
\hline & $9 M G B$ & L. longipalpis & Rio Bonito & Rio de Janeiro & $B R$ & [29] \\
\hline & $9 M G B$ & L. longipalpis & Niterói & Rio de Janeiro & & $\begin{array}{l}\text { Hamilton \& Brazil (Personal } \\
\text { communication, 2015) }\end{array}$ \\
\hline & $9 M G B$ & L. longipalpis & Barra de Guaratiba & Rio de Janeiro & $B R$ & {$[48]$} \\
\hline & $9 M G B$ & L. longipalpis & Saquarema & Rio de Janeiro & $B R$ & $\begin{array}{l}\text { Hamilton \& Brazil (Personal } \\
\text { communication, 2015) }\end{array}$ \\
\hline & $9 M G B$ & L. longipalpis & Adamantina & São Paulo & $\mathrm{BR}$ & {$[29]$} \\
\hline & $9 M G B$ & L. longipalpis & Araçatuba & São Paulo & $B R$ & {$[29]$} \\
\hline & $9 M G B$ & L. longipalpis & Bauru & São Paulo & $B R$ & [29] \\
\hline & $9 M G B$ & L. longipalpis & Dracena & São Paulo & $B R$ & {$[29]$} \\
\hline & $9 M G B$ & L. longipalpis & Jales & São Paulo & $\mathrm{BR}$ & [29] \\
\hline & $9 M G B$ & L. longipalpis & Lourdes & São Paulo & $\mathrm{BR}$ & [29] \\
\hline & $9 M G B$ & L. longipalpis & Marília & São Paulo & $\mathrm{BR}$ & [29] \\
\hline & $9 M G B$ & L. longipalpis & Oswaldo Cruz & São Paulo & $\mathrm{BR}$ & [29] \\
\hline & $9 M G B$ & L. longipalpis & Presidente Prudente & São Paulo & $\mathrm{BR}$ & [29] \\
\hline & $9 M G B$ & L. longipalpis & Promissão & São Paulo & $B R$ & {$[29]$} \\
\hline & $9 M G B$ & L. longipalpis & Salmourão & São Paulo & $B R$ & [29] \\
\hline & $9 M G B$ & L. longipalpis & Porto Nacional & Tocantins & $\mathrm{BR}$ & [126] \\
\hline & $9 M G B$ & L. longipalpis & L'Aguila & Tolima & $\mathrm{COL}$ & {$[127]$} \\
\hline & $9 M G B+C E M B-1$ & L. longipalpis & São Pedro & São Paulo & $B R$ & {$[29]$} \\
\hline
\end{tabular}


Table 1 Distribution of the different chemotypes described in America (Continued)

\begin{tabular}{|c|c|c|c|c|c|c|}
\hline \multirow[t]{5}{*}{2} & $3 \mathrm{MaH}$ & L. longipalpis & Cavunge & Bahia & $\mathrm{BR}$ & $\begin{array}{l}\text { Hamilton \& Brazil (Personal } \\
\text { communication, 2015) }\end{array}$ \\
\hline & $3 \mathrm{MaH}$ & L. longipalpis & Jacobina & Bahia & $\mathrm{BR}$ & {$[41,44]$} \\
\hline & $3 \mathrm{MaH}$ & L. longipalpis & Jequié & Bahia & $\mathrm{BR}$ & $\begin{array}{l}\text { Hamilton \& Brazil (Personal } \\
\text { communication, 2015) }\end{array}$ \\
\hline & $3 \mathrm{MaH}$ & L. pseudolongipalpis & La Rinconada & Curarigua Lara & VE & [47] \\
\hline & $3 \mathrm{MaH}$ & L. pseudolongipalpis & El Paso & Lara State & VE & [116] \\
\hline \multirow[t]{27}{*}{3} & CEMB-1 & L. longipalpis & Afonso Cláudio & Espírito Santo & $\mathrm{BR}$ & $\begin{array}{l}\text { Hamilton \& Brazil (Personal } \\
\text { communication, 2015) }\end{array}$ \\
\hline & CEMB-1 & L. longipalpis & Águas da Prata & São Paulo & $\mathrm{BR}$ & {$[29]$} \\
\hline & CEMB-1 & L. longipalpis & Barcarena & Pará & $\mathrm{BR}$ & $\begin{array}{l}\text { Hamilton \& Brazil (Personal } \\
\text { communication, 2015) }\end{array}$ \\
\hline & CEMB-1 & L. longipalpis & Camará & Pará & $\mathrm{BR}$ & $\begin{array}{l}\text { Hamilton \& Brazil (Personal } \\
\text { communication, 2015) }\end{array}$ \\
\hline & CEMB-1 & L. longipalpis & Campinas & São Paulo & $\mathrm{BR}$ & [29] \\
\hline & CEMB-1 & L. longipalpis & Espírito Santo do Pinhal & São Paulo & $\mathrm{BR}$ & [29] \\
\hline & CEMB-1 & L. longipalpis & Estrela de Alagoas & Alagoas & $\mathrm{BR}$ & {$[46]$} \\
\hline & CEMB-1 & L. longipalpis & Indaiatuba & São Paulo & $\mathrm{BR}$ & [29] \\
\hline & CEMB-1 & L. longipalpis & Ipanema & Minas Gerais & $\mathrm{BR}$ & $\begin{array}{l}\text { Hamilton \& Brazil (Personal } \\
\text { communication, 2015) }\end{array}$ \\
\hline & CEMB-1 & L. longipalpis & Jaíba & Minas Gerais & $\mathrm{BR}$ & {$[45]$} \\
\hline & CEMB-1 & L. longipalpis & Maceió & Alagoas & $\mathrm{BR}$ & $\begin{array}{l}\text { Hamilton \& Brazil (Personal } \\
\text { communication, 2015) }\end{array}$ \\
\hline & CEMB-1 & L. longipalpis & Marajó & Pará & $\mathrm{BR}$ & {$[47]$} \\
\hline & CEMB-1 & L. longipalpis & Natal & Rio Grande do Norte & $\mathrm{BR}$ & {$[47]$} \\
\hline & CEMB-1 & L. longipalpis & Pancas & Espírito Santo & $\mathrm{BR}$ & {$[48]$} \\
\hline & CEMB-1 & L. longipalpis & Passira & Pernambuco & $\mathrm{BR}$ & $\begin{array}{l}\text { Hamilton \& Brazil (Personal } \\
\text { communication, 2015) }\end{array}$ \\
\hline & CEMB-1 & L. longipalpis & Porto Nacional & Tocantins & $\mathrm{BR}$ & {$[126]$} \\
\hline & CEMB-1 & L. longipalpis & Salto & São Paulo & $\mathrm{BR}$ & [29] \\
\hline & CEMB-1 & L. longipalpis & Santarém & Pará & $\mathrm{BR}$ & {$[46]$} \\
\hline & CEMB-1 & L. longipalpis & Sobral & Ceará & & {$[46]$} \\
\hline & CEMB-1 & L. longipalpis & Socorro & São Paulo & $\mathrm{BR}$ & [29] \\
\hline & CEMB-1 & L. longipalpis & Sol da Costa & Alagoas & $\mathrm{BR}$ & {$[46]$} \\
\hline & CEMB-1 & L. longipalpis & Sorocaba & São Paulo & $\mathrm{BR}$ & [29] \\
\hline & CEMB-1 & L. longipalpis & Votorantim & São Paulo & $\mathrm{BR}$ & [29] \\
\hline & CEMB-1 & L. longipalpis & Aracajú & Sergipe & $\mathrm{BR}$ & $\begin{array}{l}\text { Hamilton \& Brazil (Personal } \\
\text { communication, 2015) }\end{array}$ \\
\hline & CEMB-1 & L. longipalpis & Cametá & Pará & $\mathrm{BR}$ & $\begin{array}{l}\text { Hamilton \& Brazil } \\
\text { (Personal communication, 2015) }\end{array}$ \\
\hline & CEMB-1 & L. longipalpis & Itamaracá & $P E$ & $\mathrm{BR}$ & $\begin{array}{l}\text { Hamilton \& Brazil } \\
\text { (Personal communication, 2015) }\end{array}$ \\
\hline & CEMB-1 & L. longipalpis & Nova Porteirinha & Minas Gerais & $\mathrm{BR}$ & $\begin{array}{l}\text { Hamilton \& Brazil (Personal } \\
\text { communication, 2015) }\end{array}$ \\
\hline 4 & CEMB-2 & L. longipalpis & Jaíba & Minas Gerais & $\mathrm{BR}$ & [45] \\
\hline
\end{tabular}

Costa and Santarém vs Sobral 2S) [46]. However, currently unrecognized taxonomic substructures could exist within these chemotypes: for example, there are significant differences in the quantities of terpene
(Chemotype 1) produced by Lapinha Cave and Sobral 1S/INS (Chemotype 5) populations and also between the Chemotype 3 Sobral $2 \mathrm{~S}$ and Santarém/Sol da Costa/ Estrela de Alagoas populations. 
Many insect semiochemicals are chiral compounds where the biological activity of each enantiomer differs, where the "unnatural" enantiomer (that not produced by the insect) may be equally active, less active (but enhancing the activity of the natural isomer) or even inhibiting the activity of the active isomer [11]. Our understanding of the stereospecificity of either CEMB-1 or CEMB-2 molecules is incomplete. All L. longipalpis collected in Estrela de Alagoas produced the same cembrenes regardless of spot type [46], acoustic differences and genetic background [48]. This may arise because the pheromones differ in the kind of CEMB-1 isomer expressed within each population. More detailed analysis is required to better reveal the true diversity of chemotypes within L. longipalpis species complex and perhaps more importantly their evolutionary significance.

The taxonomic status of L. longipalpis has been the focus of a number of studies using populations distributed over a broad geographical range spanning countries in Central and South America $[55,56]$. Several independent studies using different approaches support the species complex hypothesis in Latin America. In contrast, evidence from Brazilian populations is contradictory: depending on the molecular marker used, some studies estimated genetic distances compatible with a single species and others support the species complex hypothesis $[57,58]$. Differential rates of evolution among genes, maintenance of ancestral polymorphisms and introgression are factors that describe discordant evolutionary history, especially for very closely related species such as L. longipalpis complex [59]. Microsatellites and nuclear genes associated with sexual behavior in Drosophila such as cacophony, paralytic and period (per) genes are among the markers that have proven useful for identifying clusters of putative species [47, 48, 51, 52, 57, 58, 60-63].

Furthermore, in addition to variation in sexpheromone type [38, 43, 46] the existence of a species complex has been proposed based on results of analyses of the male courtship song $[64,65]$. The courtship song is produced by L. longipalpis during pre-mating courtship and copulation $[37,48]$ and may play a role in species recognition $[66,67]$. Copulation song analyses of L. longipalpis populations from around Brazil revealed at least six basic song types. Laboratory crosses between some of these different song types populations resulted in insemination failure $[37,38]$. An integrative study including data on copulation song, sex pheromone and molecular variation of per gene yielded two main groups: a homogeneous group producing a burst-type and CEMB-1 and a heterogeneous group producing five different pulse-song patterns (designed as P1 to P5) and four different pheromones (9MGB, 3M $\alpha \mathrm{H}, \mathrm{CEMB}-1$ and CEMB-2) [48]. A multilocus approach estimated that the two lineages split about 0.5 million years ago [59].
However, the evidence of introgression, suggest a posterior secondary contact in localities such as Sobral and probably indicate that the splitting time was not long enough ago to ensure the appearance of full reproductive isolation mechanisms. More recently, a study using a more comprehensive geographical sampling regime corroborates the existence of at least six species in Brazil based on copulation song parameters [68].

\section{The significance of pheromone for Lutzomyia longipalpis}

While the evolution of a chemical cue is a chance event, its maintenance in the population can only be sustained if its presence yields adaptive benefits, or at least if its costs are neutral. In L. longipalpis the male produced pheromone is (either directly or indirectly) implicated in species- and mate-recognition as well as in mate assessment.

\section{Not just a sex pheromone}

Male sand flies of the $L$. longipalpis species complex form crepuscular and nocturnal aggregations (or leks), which persist for many hours, on or near vertebrate hosts [69-71]. Males are attracted to host odours (kairomones) [72] even though, in contrast to females, they are not haematophagous. Field-based studies using traps demonstrated that males arrive earlier at host-sites and that their arrival is related to both hostand male-abundance [70]. Females visit leks to obtain a blood meal and to mate and are attracted to both the host kairomones and the male-produced sex pheromone [73, 74]. There is temporal separation in the arrival of males and females: females arrive later and stay for shorter periods and both female immigration and abundance are related to the distribution of males rather than the distribution of hosts [75]. In contrast, male emigration rates from the lek are inversely related to host and fly abundance suggesting that they are using semiochemicals to maintain aggregations [70]. Males also appear to retain their position at the lek in a given night and return to the same site over multiple nights [70].

Dougherty et al. [76] made the first electrophysiological recordings from ascoid sensillae on the female antennae and reported neurons sensitive to the sex pheromone. Ascoid sensillae are paired structures found on the 3rd-15th antennal segments, in both sexes [77]. In a laboratory study, that coupled capillary gas chromatography with electrophysiological recordings from ascoid sensillum receptor cells it was demonstrated that receptor cells from both male and female ascoid sensillae responded only to the major component $(3 \mathrm{M} \alpha \mathrm{H})$ of the sex gland extract of $L$. longipalpis from Jacobina Brazil [78]. Behavioral experiments also confirmed that both males and females from the Jacobina population 
flew upwind in a wind tunnel towards a filter paper disk treated with tergal gland extract, pure $(1 S, 3 S, 7 R)$-3-methyl- $\alpha$-himachalene or the synthetic mixture of eight isomers thus supporting the proposal that $3 \mathrm{M} \alpha \mathrm{H}$ derived from L. longipalpis Jacobina males has a dual function in promoting male aggregations as well as serving as a sex pheromone for females. Subsequent field studies with a different chemotype corroborated this proposal as synthetic pheromone traps containing a racemic mixture of 9MGB attracted flies of both sexes [79] even when used in conjunction with insecticide sprayed animal houses [80].

When combined, the empirical data suggests that the glandular sex pheromone functions to promote both aggregation of males and attraction of females. This represents both the first and possibly second level of mate choice: namely, species recognition and sex identification. The final level of choice is individual identification and the degree to which pheromones contribute to female mating preference is less well understood. It is conceivable that a male's mating success is directly related to pheromone gland content [81], however it may be related to other traits, such as courtship behavior, copulatory courtship song [68] or other pheromones such as cuticular hydrocarbons (CHCs) [82]. In practice it is likely that multiple factors contribute to male mating success, however if pheromones are utilized in mate choice then theoretically it is predicted they should be honest signals and thus most likely to be costly to produce. An overview of the L. longipalpis sex-aggregation pheromone communication system from a pheromone biosynthesis perspective and showing the different chemotypes produced and the apparatus involved in perception of pheromone can be seen in Fig. 3.

\section{Individual variation in pheromone production}

Early behavioral studies revealed variation in male mating success related to age and although not explicitly demonstrated, this may relate to variation in pheromone production [81]. Recent chemical analyses of age-related pheromone content in males confirm a gradual increase in pheromone production in synchrony with the pheromone gland cells maturation [83]. This study did not examine the pattern in even older males, thus whether a decline in pheromone content commensurate with senescence is unknown [81]. Nonetheless, age-related signal degradation is one mechanism that honesty can be maintained within the system and this may be adaptive in L. longipalpis because on average, older males sire fewer viable offspring [81]. It is interesting to note that in L. longipalpis males, the genitalia undergo a $180^{\circ}$ rotation after emergence, taking $24 \mathrm{~h}$ for the insects to become sexually mature [28] and pheromone biosynthesis commences around $12 \mathrm{~h}$ after emergence, increasing until

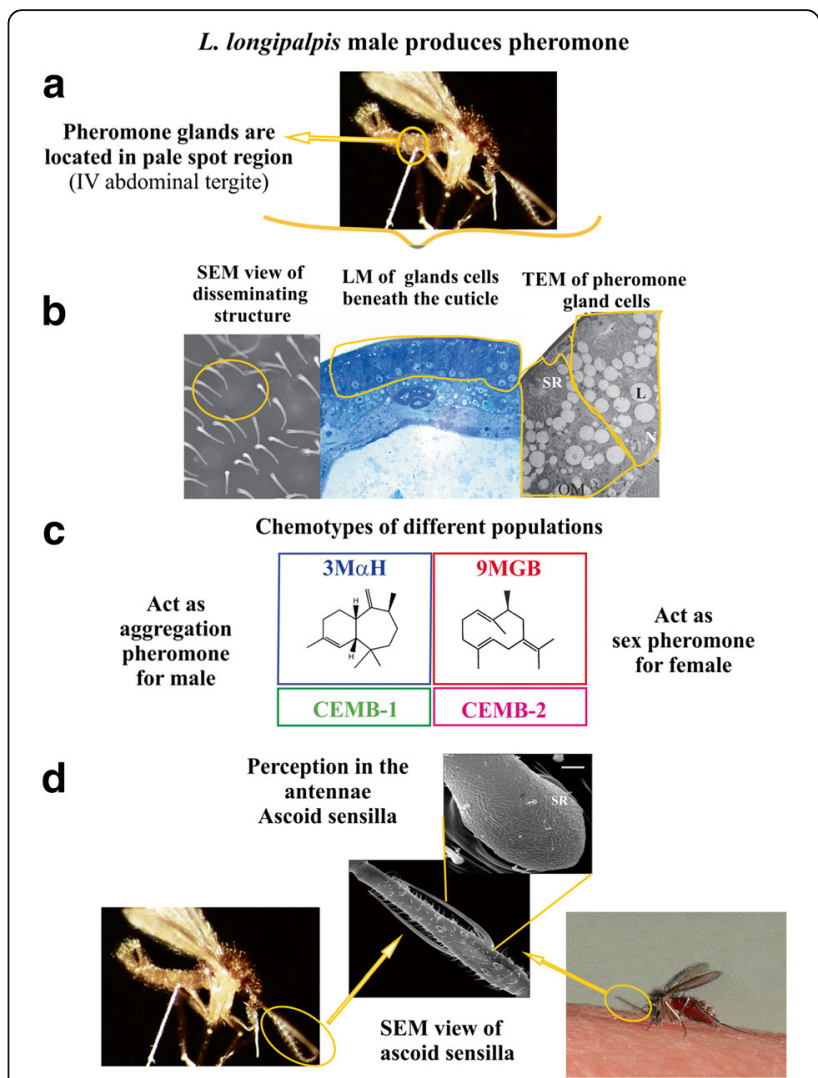

Fig. 3 Lutzomyia longipalpis aggregation-sex pheromone communication system. a The aggregation-sex pheromones is produced by males in glands located in the pale spots in the third and/or fourth abdominal tergites. b Scanning Electron microscopy (SEM) of the cuticular papules with a central pore disseminating structures located in pale spots. The secretion is produced by pheromone gland cells grouped beneath the cuticle showed in light microscopy (LM). Details of two large columnar secretory cells can be observed in this transmission electron microscopy (TEM). Each gland cell is connected to the exterior via a small cuticular duct and present two distinct parts: a basal region with vacuoles containing lipids ( $L$ ) and an apical region with an end apparatus and a small reservoir (SR). c The main component of the pheromone differs among populations and represent different chemotypes. $\mathbf{d}$ The pheromone is perceived by the paired ascoid sensilla present in antennae of both male and female showed in SEM. The pheromone functions for male as an aggregation pheromone and as sex pheromone by female

three days of age and then stabilizing thereafter [83]. Noteworthy also then, is the fact that L. longipalpis, males commence the adult stage of their lives with no ability to attract females, at least from a distance and, if the pheromone signal deteriorates with old age, they are similarly less capable of attracting females as they senesce. Indeed, the nature of signal production in L. longipalpis may be one of the key reasons why a lek-mating aggregation strategy is adaptive for both sexes. Younger males (who are incapable of high pheromone output) and older males (if their signal does indeed deteriorate with age) might 
benefit from parasitizing the communication output of average-age individuals and females are provided with a choice of males [84]. Whether female mating preferences are related directly to the sex pheromone or also include $\mathrm{CHC}$ profiles (as has been demonstrated for other insects [85-87]) is unknown but their presence has been proposed in L. longipalpis [82, 88] and has been demonstrated for related sand fly species [89-93]. However, whether or not some of those $\mathrm{CHC}$ have pheromonal properties is not known. Selecting for specific lines based on chemical traits are untested in L. longipalpis but this might prove a way of determining the significance of the direction and force of selection on pheromones and chemoreception.

\section{Cost of production - sexual selection}

Understanding the costs of pheromone production remain largely elusive across invertebrates and whether signals that are involved in reproduction, and have presumably evolved through sexual selection, are required to be costly to be honest remains a subject of considerable debate (for a recent comprehensive review see, Steiger \& Stökl [21]). Some chemical signals might be expressed in relation to body condition or vary with age; others may more reliably reflect an individual's genetic quality. The costs of production are rarely demonstrated in insects (but see Johansson et al. [94]), however these can be inferred indirectly in species where signal production commences after adult eclosion (as is the case for L. longipalpis [83]). Recent transcriptomics and proteomics studies have revealed much about the biosynthetic pathway for glandular secretions in Lutzomyia including the specific enzyme pathways involved in sesquiterpenoid biosynthesis [95, 96]. It was observed in L. longipalpis that if the diet is changed, e.g. glucose to fructose, there is a change in the amount of pheromone produced (Hamilton, unpublished). These results might suggest that pheromone production will be optimal if diet is optimal.

\section{Distinct evolutionary forces acting on L. longipalpis aggregation-sex pheromones}

A key question that remains is why the pheromone composition varies across populations? The most parsimonious explanation is that it provides an efficient means by which closely related sympatric subspecies can limit hybridization $[52,59]$. Only a small number of hybrids exist in sympatric populations in nature [29, 46]. Field [54] and laboratory [36-38] data indicate that Brazilian populations of L. longipalpis respond to the male pheromone in a sibling speciesspecific manner. Therefore, the male sex pheromones may act as a pre-mating isolation barrier, reducing non-productive mating encounters and therefore may be important influences on speciation in the L. longipalpis complex. However, the evidence on whether the chemical cues observed are sufficiently isolating is not strong and the evidence that currently exists suggests that short-range behavioral traits such as courtship [82] or songs [59, 64, 68] play an important additional species isolating role. From an evolutionary perspective it is likely that chemical shifts may drive significant reproductive diversification and ultimately speciation $[5,9]$.

Current evidence regarding temporal variation in release is also limited. Ultrastructural analysis of male unicellular sex pheromone glands beneath the cuticle shows a small structure, the end apparatus surrounded by secretory cells that become highly vacuolated as the male sand fly matures. Therefore, the potential to accumulate pheromones in cuticular glands is small but the rather larger amounts of lipid containing vaculoles suggests that although pheromone production and release may be not be instantaneous but more gradual [32] Small, but potentially significant variation in locomotor activity is observed across sympatric populations of $L$. longipalpis [97], however further studies exploring simultaneously circadian rhythms and pheromone release are necessary to exclude the hypothesis of some kind of temporal partitioning of communication channels such as that observed in moths [16, 98].

The direction of selection for pheromone output has not been tested explicitly in L. longipalpis but several studies suggest that males benefit from attending aggregations (because larger leks attract more females) and that females also gain indirect benefits through a greater number of mate choice options. The evolution of a male pheromone that attracts other males is only sustainable if this also leads to an increase in male reproductive success, unless the production of that pheromone was cost neutral. The fact that males take multiple days to achieve maximal pheromone output suggests that there are likely costs and thus neutrality cannot be invoked. Thus, we must assume that there are adaptive benefits to its production and they must include fitness benefits such as increased mating success and hence offspring production. Although attraction of other males does not seem to be beneficial for the emitter, it may evolve if the cost of "not calling" is larger than the cost of "having to share" the responding female [99]. Moreover, aggregations can facilitate mate-finding, resulting in energetic savings on search costs. However, male signaling in $L$. longipalpis may confer advantages to females other than just for mate finding, particularly because lek formation often occurs on or near hosts $[69,100]$ and thus females gain the necessary resources for offspring production. Laboratory experiments also suggest a synergistic effect (in terms of female attraction) when the sex-pheromone and the host odor are combined [73, 74, 101]. This is in accordance with Landolt's hypothesis that mate-finding 
systems based on male-produced sex attractants are usually associated with feeding and oviposition sites and thus serve to compensate for the risks and increased energy expenditure associated with mate searching [102]. Accordingly, many species demonstrate an increased response to specific aggregation pheromones when they are accompanied by co-attractants [99]. The benefits that an individual male accrues from lekking are likely determined by his individual quality, whereby highquality males in large leks gain access to more females [75]. In L. longipalpis females do not mate readily a second time (at least during a single gonotrophic cycle) [103]. Behavioral observations revealed a reduction in mating frequency of copulated females [103, 104] and transcriptome analyses from male sand fly reproductive organs that identify ESTs encoding orthologs of Seminal Fluid Proteins (SFPs) [105], indicate the presence of putative L. longipalpis SFPs which may reduce sexual mating frequency of copulated females (like in Drosophila melanogaster) $[106,107]$. The presence of a mating plug has been observed in the spermatheca of other sand flies such as $P$. perniciosus, $P$. papatasi [108] and $P$. duboscqui [109]. While not explicitly tested it probably acts to reduce, if not prevent, multiple mating in females and is likely to be driven by male-imposed means through sexual conflict.

\section{Dispersion of populations with different pheromones}

A gap in the current literature is that little is known regarding the evolutionary pathway of pheromone synthesis across the L. longipalpis species complex. In moths, changes in enzymes involved in the synthesis pathway of pheromones do produce different pheromones in closely related species $[20,110,111]$. In L. longipalpis it is conceivable that an analogous process is occurring. GonzálezCaballero [95] and colleagues used transcriptome and proteome data to explore the enzymatic cascade from the sex pheromone gland. Molecules which are associated with enzymes of the mevalonate pathway were found in the pheromone gland. However, the later steps of production of isoprenoid compounds led to different end products from those found in other insects. Although there is little information available on the biosynthesis of cyclic sesquiterpene or methylsesquiterpene compounds in insects, mutations or other genetic events, at least in one enzyme might result in different pheromones. Recently the characterization of genes that cause qualitative changes in insect pheromones was described in detail for the Hymenoptera [112]. Elegant experiments provide support for the idea that new pheromone compounds can emerge from modifications in existing signaling molecules. Furthermore, and perhaps most interesting is that sex pheromone receptors do not appear to immediately respond to novel pheromone compounds within the existing pheromone blend. This provides a mechanism by which new pheromone components may initially escape from selection exerted by the receivers and, concomitantly, receptors would have a time to associate the new compound with conspecific mates and to be recognized it as part of the species-specific chemical signal [112].

Associations between Brazilian populations and Central and South America populations could indicate that the diterpene form has evolved from the widespread 9MGB type. To date, the diterpene producing-form has not been found outside of Brazil and all sex pheromones typed in Venezuela, Honduras, Guatemala, Colombia, Bolivia, Paraguay and Argentina, as well as several Brazilian populations (e.g. Lapinha, Teresina, Barra de Guaratiba) [38, 47, 113-115] were the 9MGB type. An exception in America is the L. pseudolongipalpis (also belonging to the L. longipalpis complex) that produces $3 \mathrm{M \alpha H}$, the same main component as the Jacobina $L$. longipalpis population from Brazil [116]. Clearly, the type of sex pheromone released by the males overrides geographical distance effects upon the phylogeographic structure of L. longipalpis. Based on ecological distribution alone, one would predict that 9MGB is the ancestral chemotype in L. longipalpis across the savannahs of South America, followed by subsequent speciation to either $3 \mathrm{M} \alpha \mathrm{H} / \alpha \mathrm{H}$ or CEMB [47].

Lutzomyia longipalpis has an extensive and patchy distribution from southern Mexico to Argentina, occurring in diverse ecological conditions such as dry habitats, humid forests [117], but also in urban areas [118]. It remains a challenge to understand the evolutionary history of this group and the mechanism underlying its success in dispersion and adaptation, despite its limited flight range [100, 119, 120]. How geographical barriers [121] and, more recently, anthropogenic environmental changes and activities have contributed to the evolution of sibling species remains a future challenge [26]. Molecular analyses and geological history [59, 121] will aid our understanding of populations distributions but these need to be coupled with studies of variation in traits involved in mating such as copulation songs $[64,65,68]$ and chemical communication [29, 46, 47]. These latter factors have undoubtedly played (and continue to play) a significant role in maintaining reproductive isolation among the different sibling species $[48,55,60]$.

Finally, it is unclear whether there are any general epidemiological implications associated with the observed variation in chemotype such as that hypothesized by Casanova [29]. An obvious disadvantage to rapid adaptation of the components of the sex pheromone is that this makes it far trickier to detect and/or control using synthetic chemical baits, unless the different chemotypes are key signature pheromones that operate within the species complex. Thus, a thorough understanding of the selective pressures and underlying mechanisms that 
generates shifts in the composition of the sex pheromone is clearly of paramount importance from both an evolutionary but an epidemiological perspective.

\section{Presence of papules in other sand fly species}

The subfamily Phlebotominae is very diverse and widely spread in the world, found in different ecological environments and continents, with more than 1,000 species known. The phylogenetic classification used by our group recognize different subdivisions within this subfamily which includes the presence or absence of papules in the abdominal tergites in the identification key [122, 123]. It is interesting to note that the papules were described by microscopy studies in different species of the family Psychodidae [32-34, 124, 125]. However, corresponding behavioral or chemical studies are largely absent. Given this, we are unable to conclude that papules always act as a pheromone disseminating structure, although a minority of studies indicates some relationship between the papule and the presence of pheromone. If we analyze among different groups of sand flies the presence of papules and put it in a phylogenetic tree, parsimony suggests that their presence is a primitive character and these papules were thus lost in some groups. Even in a more primitive Psychodidae group such as the Bruchomyinae the papules are present, indicating that their presence in more recent groups such as Lutzomyia is not exclusive or a novelty. Similarly, in the same subtribes of the subfamily Phlebotominae, we can find species with and without papules (Fig. 4), for example in the subtribes Brumptomyiina, Sergentomyiina, Lutzomyiina and Psychodopygina. It is unknown whether the tribe Hertigiini, the subtribe Australophlebotomina or the genus Oligodontomyia has papules; however limited evidence suggests that at least some species in the subtribe Phlebotomina do not have papules, but we cannot be sure if papules are absent in all species of this group or whether their absence reflects a lack of sampling effort. Due to the fragmented disposition of the papules across the different phylogenetic groups, it is challenging to understand why the presence of pheromones is not consistent particularly as they are so advantageous. Further studies are necessary to better understand the evolution and the loss of pheromone cues in different species of seemingly closely related Phlebotominae.

\section{Conclusions}

Species complexes are important models for understanding the role of chemical divergence in speciation. Here, we used an evolutionary framework to review the history of aggregation-sex pheromones within the L. longipalpis species complex. In this group, aggregation-sex pheromones are produced by males during territorial courtship displays. The male produced pheromone (in synergy with host odors) attracts haematophagous

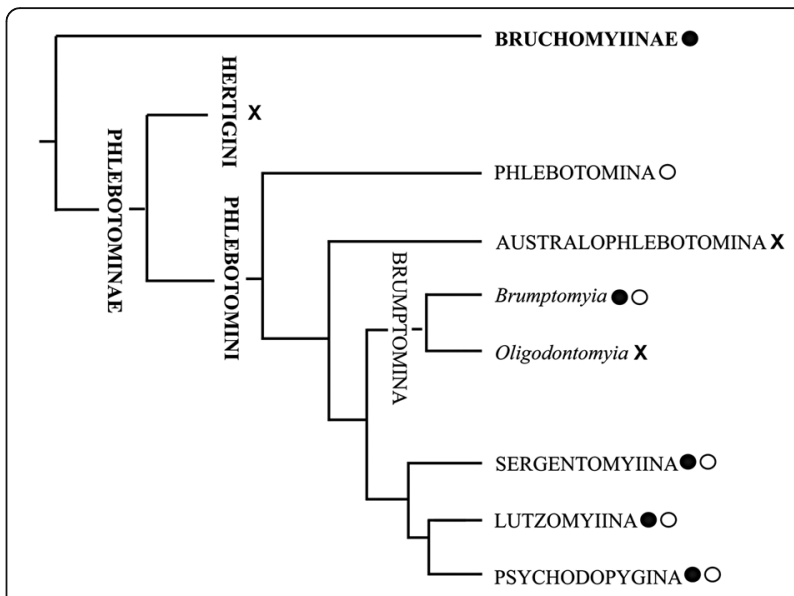

Fig. 4 Phylogenetic tree of the family Psychodidae including the different subtribes of the subfamily Phlebotominae indicating the presence $(\cdot)$ or the absence $(\mathbf{o})$ of papule in the abdominal tergites of different groups as well as the lack of studies (x). Modified from Galati et al. [123]

females to a common site of copulation and feeding. Observations of variation in the sex-pheromone coupled with knowledge of geographical distribution of sandflies indicates four distinct chemotypes; (S)-9-methylgermacrene- $B$, the most widespread in South and Central America, followed by cembrene-1, cembrene- 2 and $(1 S, 3 S, 7 R)$-3-methyl-alpha-himachalene. It is possible that more taxonomic substructures exist within the current chemotypes: potentially, a fifth chemotype has been identified based on variation in the amount of specific terpenes present and our understanding of the stereospecificity of cembrene molecules remains incomplete. Although those chemotypes exist in sympatry, the chemical hybrids which can be generated in laboratory experiments, are rare in nature. Field and laboratory studies show that there is no significant cross attraction between different chemotypes and thus it can reasonably be concluded that pheromone communication (coupled with short-range stereotypic courtship behaviors or male courtship song) has contributed to divergence and potentially speciation in the L. longipalpis complex. The fact that males take multiple days to achieve maximum pheromone output suggests that there is a significant cost of pheromone production and recent transcriptomics and proteomics studies have revealed more about the biosynthetic pathway, but the precise evolutionary pathway across the L. longipalpis complex in unknown. Thus, we must assume that there are adaptive benefits of pheromone production including fitness benefits such as increased mating success and hence offspring production, contributing therefore to mate assessment. It remains a challenge to understand the evolutionary history of this group and the mechanisms underpinning its success in dispersion and adaptation. 


\section{Abbreviations}

1S: One spot phenotype; 2S: Two spot phenotype; 3MaH: (1S,3S,7R)-3-methyl-ahimachalene; 9MGB: (S)-9-methylgermacrene-B; AVL: American visceral leishmaniasis; CEMB-1: Cembrene-1; CEMB-2: Cembrene-2; CHCs: Cuticular hydrocarbons; INS: Intermediate forms; SFPs: Seminal fluid proteins

\section{Acknowledgments}

The authors would like to thank Cleilton Sampaio de Farias for the map construction and Genilton José Vieira for the L. longipalpis female photography. We would like to dedicate this review to three great pioneering researchers: Richard D. Ward (in memoriam), Bruce Alexander (in memoriam) and Alexandre A. Peixoto (in memoriam) for all their work on the L. longipalpis species complex.

\section{Funding}

The authors would like to thank the financial support for the research from Wellcome Trust (JGCH), Conselho Nacional de Desenvolvimento Científico e Tecnológico - CNPq (RPB), Coordenação de Aperfeiçoamento de Pessoal de Nível Superior - CAPES (ASA) and Instituto Oswaldo Cruz (DBS, ASA and RPB).

\section{Availability of data and materials}

Not applicable.

\section{Authors' contributions}

CNS, DBSD, ASA and TMJ wrote and reviewed the manuscript. CNS and ASA conceived the figures. JGCH and RPB provided unpublished data on pheromone characterization of different populations and reviewed the manuscript. All authors read and approved the final version of the manuscript.

\section{Competing interests}

The authors declare that they have no competing interests.

\section{Consent for publication}

Not applicable.

\section{Ethics approval and consent to participate}

Not applicable.

\section{Author details}

${ }^{1}$ Departamento de Biologia Celular e Molecular, Instituto de Biologia Universidade Federal Fluminense, Outeiro de São João Batista $s / n$, Valonguinho, Centro, Niterói 24.020-150, RJ, Brazil. ²Departamento de Bioquímica, Instituto de Biologia Roberto Alcântara Gomes, Universidade do Estado do Rio de Janeiro, Rio de Janeiro CEP: 20.551-030, RJ, Brazil. ${ }^{3}$ Laboratório de Biologia Molecular de Insetos, Instituto Oswaldo Cruz, FIOCRUZ, Rio de Janeiro 21040-360, RJ, Brazil. ${ }^{4}$ Division of Biomedical and Life Sciences, School of Health and Medicine, Lancaster University, Lancaster, UK. ${ }^{5}$ Laboratório de Doenças Parasitárias, Instituto Oswaldo Cruz, FIOCRUZ, Rio de Janeiro 21040-900, RJ, Brazil. '5 School of BioSciences, University of Melbourne, Melbourne 3010, Australia.

\section{Received: 17 May 2016 Accepted: 1 November 2016} Published online: 14 November 2016

\section{References}

1. Butenandt A, Beckman R, Stamm D, Hecker E. Uber den sexual lockstoff des seidenspinners Bombyx mori. Reindarstelling und konstitution. Z Naturforsch. 1959;14b:283-4.

2. Karlson P, Luscher M. Pheromones': a new term for a class of biologically active substances. Nature. 1959:183:55-6.

3. Karlson P, Butenandt A. Pheromones (ectohormones) in insects. Ann Rev Entomol. 1959:4:39-58.

4. El-Sayed AM. The Pherobase: database of pheromones and semiochemicals. http://www.pherobase.com. Accessed 5 May 2016.

5. Symonds MRE, Elgar MA. The evolution of pheromone diversity. Trends Ecol Evol. 2008;23:220-8.

6. Johansson BG, Jones TM. The role of chemical communication in mate choice. Biol Rev Camb Philos Soc. 2007:82:265-89.

7. Cardé RT. Defining attraction and aggregation pheromones: teleological versus functional perspectives. J Chem Ecol. 2014;40:519-20.
8. Gomez-Diaz C, Benton R. The joy of sex pheromones. EMBO Rep. 2013;14:874-83.

9. Smadja C, Butlin RK. On the scent of speciation: the chemosensory system and its role in premating isolation. Heredity. 2009;102:77-97.

10. Wyatt TD. Fifty years of pheromones. Nature. 2009;457:262-3.

11. Mori K. Stereochemical studies on pheromonal communications. Proc Jpn Acad Ser B Phys Biol Sci. 2014;90:373-88.

12. Ando T, Yamakawa R. Chiral methyl-branched pheromones. Nat Prod Rep. 2015;32:1007-41.

13. Yew JY, Chung H. Insect pheromones: an overview of function, form, and discovery. Prog Lipid Res. 2015;59:88-105.

14. Wyatt TD. How animals communicate via pheromones. Am Sci. 2015;103:114-21.

15. Wicker-Thomas C. Evolution of insect pheromones and their role in reproductive isolation and speciation. Ann Soc Entomol Fr. 2011;47:55-62.

16. Groot AT. Circadian rhythms of sexual activities in moths: a review. Front Ecol Evol. 2014;2:1-21.

17. Di Cara F, King-Jones K. How clocks and hormones act in concert to control the timing of insect development. Curr Top Dev Biol. 2013;105:1-36.

18. Mitchell RF, Reagel PF, Wong JCH, Meier LR, Silva WD, Mongold-Diers J, et al. Cerambycid beetle species with similar pheromones are segregated by phenology and minor pheromone components. J Chem Ecol. 2015;41:431-40.

19. Baker TC. Balanced olfactory antagonism as a concept for understanding evolutionary shifts in moth sex pheromone blends. J Chem Ecol. 2008;34:971-81.

20. Roelofs WL, Liu W, Hao G, Jiao H, Rooney AP, Linn CE. Evolution of moth sex pheromones via ancestral genes. Proc Natl Acad Sci USA. 2002;99: 13621-6.

21. Steiger S, Stökl J. The role of sexual selection in the evolution of chemical signals in insects. Insects. 2014;5:423-38.

22. Bergen E Van, Brakefield PM, Heuskin S, Zwaan BJ, Nieberding CM, B PRS. The scent of inbreeding: a male sex pheromone betrays inbred males. Proc R Soc B. 2013:280:20130102.

23. Palatnik-de-Sousa CB, Day MJ. One Health: The global challenge of epidemic and endemic leishmaniasis. Parasit Vectors. 2011:4:197.

24. Alvar J, Vélez ID, Bern C, Herrero M, Desjeux P, Cano J, et al. Leishmaniasis worldwide and global estimates of its incidence. PLoS One. 2012:7:e35671.

25. Lainson R, Rangel EF. Lutzomyia longipalpis and the eco-epidemiology of American visceral leishmaniasis, with particular reference to Brazil: a review. Mem Inst Oswaldo Cruz. 2005;100:811-27.

26. Brazil RP. The dispersion of Lutzomyia longipalpis in urban areas. Rev Soc Bras Med Trop. 2013;46:263-4.

27. Deane L, Deane M. Visceral leishmaniasis in Brazil: geographical distribution and transmission. Rev Inst Med Trop. 1962;4:198-212.

28. Young DG, Duncan MA. Guide to the identification and geographic distribution of Lutzomyia sand flies in Mexico, the West Indies, Central and South America. J Biol Sci. 1994;14:79-94.

29. Casanova C, Colla-Jacques FE, Hamilton JGC, Brazil RP, Shaw JJ. Distribution of Lutzomyia longipalpis chemotype populations in São Paulo State, Brazil. PLoS Negl Trop Dis. 2015:9:e0003620.

30. Mangabeira O. Sobre a sistemática e biologia dos flebótomos do Ceará. Rev Bras Mal Doenças Trop. 1969;21:3-26.

31. Lane RP, Ward RD. The morphology and possible function of abdominal patches in males of 2 forms of the leishmaniasis vector Lutzomyia longipalpis (Diptera Phlebotominae). Cah ORSTOM (Office la Rech Sci Tech Outre-Mer) Ser Entomol Medicale Parasitol. 1984;22:245-9.

32. Spiegel CN, Brazil RP, Soares MJ. Ultrastructure of male sex pheromone glands in abdominal tergites of five Lutzomyia sandfly species (Diptera: Psychodidae). Arthropod Struct Dev. 2002;30:219-27.

33. Lane RP, de Bernardes D S. Histology and ultrastructure of pheromone secreting glands in males of the phlebotomine sandfly Lutzomyia longipalpis. Ann Trop Med Parasit. 1990;84:53-61.

34. Barth R. Sôbre o aparelho genital interno do macho de Phlebotomus longipalpis (Lutz et Neiva, 1912): (Diptera, Psychodidae). Mem Inst Oswaldo Cruz. 1961:59:23-36.

35. Ward R, Morton I, Lancaster V, Smith P, Swift A. Bioassay as an indicator of pheromone communication in Lutzomyia longipalpis (Diptera: Psychodidae). In: Hart D, editor. Leishmaniasis: the current status new strategies for control. Greece: Springer; 1989. p. 235-43.

36. Ward RD, Ribeiro AL, Ready PD, Murtagy A. Reproductive isolation between different forms of Lutzomyia longipalpis (Lutz \& Neiva), (Diptera Psychodidae), the vector of Leishmania donovani chagasi Cunha \& Chagas 
and its significance to kalaazar distribution in South America. Mem Inst Oswaldo Cruz. 1983;78:269-80.

37. Souza NA, Andrade-Coelho CA, Vigoder FM, Ward RD, Peixoto AA. Reproductive isolation between sympatric and allopatric Brazilian populations of Lutzomyia longipalpis s.l. (Diptera: Psychodidae). Mem Inst Oswaldo Cruz. 2008;103:2016-9.

38. Ward R, Phillips A, Burnet B, Marcondes C. The Lutzomyia longipalpis complex: reprodution and distribution, MW serv biosyst haematop insects. Oxford: Oxford University Press; 1988. p. 258-69.

39. Lane RP, Phillips A, Molyneux DH, Procter G, Ward RD. Chemical analysis of the abdominal glands of two forms of Lutzomyia longipalpis: site of a possible se pheromone? Ann Trop Med Parasit. 1985;79:225-9.

40. Phillips A, Ward R, Ryan L, Molyneux DH, Lainson R, Shaw JJ. Chemical analysis of compounds extracted from the tergal "spots" of Lutzomyia longipalpis from Brazil. Acta Trop. 1986;43:271-6.

41. Hamilton JG, Dougherty MJ, Ward RD. Sex pheromone activity in a single component of tergal gland extract of Lutzomyia longipalpis (Diptera: Psychodidae) from Jacobina. J Chem Ecol. 1994;20:141-51.

42. Hamilton JGC, Dawson GW, Pickett JA. 9-Methylgermacrene-B; Proposed structure for novel homosesquiterpene from the sex pheromone glands of Lutzomyia longipalpis (Diptera: Psychodidae) from Lapinha, Brazil. J Chem Ecol. 1996;22:1477-91.

43. Hamilton JG, Ward RD, Dougherty MJ, Maignon R, Ponce C, Ponce E, et al. Comparison of the sex-pheromone components of Lutzomyia longipalpis (Diptera:Psychodidae) from areas of visceral and atypical cutaneous leishmaniasis in Honduras and Cost Rica. Ann Trop Med Parasitol. 1996;90:533-41.

44. Hamilton JGC, Hooper AM, Pickett JA, Mori K, Sano S. 3-Methyl-ahimachalene is confirmed, and the relative stereochemistry defined, by synthesis as the sex pheromone of the sandfly Lutzomyia longipalpis from Jacobina, Brazil. Chem Commun. 1999:4:355-6.

45. Hamilton JGC, Brazil RP, Maingon R. A fourth chemotype of Lutzomyia longipalpis (Diptera: Psychodidae) from Jaibas, Minas Gerais State, Brazil. J Med Entomol. 2004;41:1021-6.

46. Hamilton JGC, Maingon RDC, Alexander B, Ward RD, Brazil RP. Analysis of the sex pheromone extract of individual male Lutzomyia longipalpis sandflies from six regions in Brazil. Med Vet Entomol. 2005;19:480-8.

47. Watts PC, Hamilton JGC, Ward RD, Noyes HA, Souza NA, Kemp SJ, et al. Male sex pheromones and the phylogeographic structure of the Lutzomyia longipalpis species complex (Diptera: Psychodidae) from Brazil and Venezuela. Am J Trop Med Hyg. 2005;73:734-43.

48. Araki AS, Vigoder FM, Bauzer LGSR, Ferreira GEM, Souza NA, Araújo IB, et al. Molecular and behavioral differentiation among Brazilian populations of Lutzomyia longipalpis (Diptera: Psychodidae: Phlebotominae). PLoS Negl Trop Dis. 2009;3:e365.

49. Hamilton JGC, Hooper A, Ibbotson H, Kurosawa S, Mori K, Muto SE et al. 9-Methylgermacrene- $B$ is confirmed as the sex pheromone of the sandfly Lutzomyia longipalpis from Lapinha, Brazil, and the absolute stereochemistry defined as S. Chem Commun. 1999;23:2335-6.

50. Brazil RP, Hamilton JGC. Isolation and identification of 9-methylgermacreneB as the putative sex pheromone of Lutzomyia cruzi (Mangabeira, 1938) (Diptera: Psychodidae). Mem Inst Oswaldo Cruz. 2002;97:435-6.

51. Santos MFC, Ribolla PEM, Alonso DP, Andrade-Filho JD, Casaril AE, Ferreira AMT, et al. Genetic structure of Lutzomyia longipalpis populations in Mato Grosso do Sul, Brazil, based on microsatellite markers. PLoS One. 2013;8:e74268.

52. Maingon RDC, Ward RD, Hamilton JGC, Noyes HA, Souza N, Kemp SJ, et al. Genetic identification of two sibling species of Lutzomyia longipalpis (Diptera: Psychodidae) that produce distinct male sex pheromones in Sobral, Ceará State, Brazil. Mol Ecol. 2003;12:1879-94.

53. Ward RD, Morton IE. Pheromones in mate choice and sexual isolation between siblings of Lutzomyia longipalpis (Diptera:Psychodidae). Parassitologia. 1991;33(Suppl):527-33.

54. Carter V, Bray D, Borges-Alves G, E D, Courtenay O, Brazil R, et al. Sex pheromones as a pre-mating species isolation on Barrier in Brazil. In: Rosa J, Fernández MS, Parra M, editors. 8th Int Symp Phlebotomine Sandflies. Foz do Iguaçu, Brazil; 2014. p. ID 14-O Taxonomy \& Phylogeny.

55. Bauzer LGSR, Souza NA, Maingon RDC, Peixoto AA. Lutzomyia longipalpis in Brazil: a complex or a single species? a mini-review. Mem Inst Oswaldo Cruz. 2007;102:1-12

56. Uribe S. The status of the Lutzomyia longipalpis species complex and possible implications for Leishmania transmission. Mem Inst Oswaldo Cruz. 1999;94:729-34
57. Bauzer LGSR, Souza NA, Ward RD, Kyriacou CP, Peixoto AA. The period gene and genetic differentiation between three Brazilian populations of Lutzomyia longipalpis. Insect Mol Biol. 2002;11:315-23.

58. Bottecchia M, Oliveira SG, Bauzer LGSR, Souza NA, Ward RD, Garner KJ, et al. Genetic divergence in the cacophony IVS6 intron among five Brazilian populations of Lutzomyia longipalpis. J Mol Evol. 2004;58:754-61.

59. Araki AS, Ferreira GEM, Mazzoni CJ, Souza NA, Machado RC, Bruno RV, et al. Multilocus analysis of divergence and introgression in sympatric and allopatric sibling species of the Lutzomyia longipalpis complex in Brazil. PLoS Negl Trop Dis. 2013;7:e2495.

60. Maingon RDC, Ward RD, Hamilton JGC, Bauzer LGSR, Peixoto AA. The Lutzomyia longipalpis species complex: does population sub-structure matter to Leishmania transmission? Trends Parasitol. 2008;24:12-7.

61. Bauzer LGSR, Gesto JSM, Souza NA, Ward RD, Hamilton JG, Kyriacou C, et al. Molecular divergence in the period gene between two putative sympatric species of the Lutzomyia longipalpis complex. Mol Biol Evol. 2002;19:1624-7.

62. Lins RMMA, Souza NA, Peixoto AA. Genetic divergence between two sympatric species of the Lutzomyia longipalpis complex in the paralytic gene, a locus associated with insecticide resistance and lovesong production. Mem Inst Oswaldo Cruz. 2008;103:736-40.

63. Lima Costa CJ, Freitas M, Santiago Figueirêdo CJAN, da Silva L, Marcondes C, Dias R, et al. Genetic structuring and fixed polymorphisms in the gene period among natural populations of Lutzomyia longipalpis in Brazil. Parasit Vectors. 2015;8:193.

64. Souza NA, Vigoder FM, Araki AS, Ward RD, Kyriacou CP, Peixoto AA. Analysis of the copulatory courtship songs of Lutzomyia longipalpis in six populations from Brazil. J Med Entomol. 2004;41:906-13.

65. de Souza NA, Ward RD, Hamilton JGC, Kyriacou CP, Peixoto AA. Copulation songs in three siblings of Lutzomyia longipalpis (Diptera: Psychodidae). Trans R Soc Trop Med Hyg. 2002;96:102-3.

66. Ritchie M, Halsey E, Gleason J. Drosophila song as a species-specific mating signal and the behavioural importance of Kyriacou \& Hall cycles in D. melanogaster song. Anim Behav. 1999;58:649-57.

67. Reinhold K. Variation in acoustic signalling traits exhibits footprints of sexual selection. Evolution. 2011;65:738-45.

68. Vigoder FM, Souza NA, Brazi RP, Bruno RV, Costa PL, Ritchie MG, et al. Phenotypic differentiation in love song traits among sibling species of the Lutzomyia longipalpis complex in Brazil. Parasit Vectors. 2015;8:290.

69. Quinnell RJ, Dye C. An experimental study of the peridomestic distribution of Lutzomyia longipalpis (Diptera, Psychodidae). Bull Entomol Res. 1994:84:379-82.

70. Kelly DW, Dye C. Pheromones, kairomones and the aggregation dynamics of the sandfly Lutzomyia longipalpis. Anim Behav. 1997;53:721-31.

71. Jones T, Hamilton J. A role for pheromones in mate choice in a lekking sandfly. Anim Behav. 1998;56:891-8

72. Hamilton JG, Ramsoondar TM. Attraction of Lutzomyia longipalpis to human skin odours. Med Vet Entomol. 1994:8:375-80.

73. Nigam $Y$, Ward RD. The effect of male sandfly pheromone and host factors as attractants for female Lutzomyia longipalpis (Diptera: Psychodidae). Physiol Entomol. 1991;16:305-12.

74. Morton IE, Ward RD. Laboratory response of female Lutzomyia longipalpis sandflies to a host and male pheromone source over distance. Med Vet Entomol. 1989:3:219-23.

75. Jones TM, Quinnell RJ. Testing predictions for the evolution of lekking in the sandfly, Lutzomyia longipalpis. Anim Behav. 2002:63:605-12.

76. Dougherty MJ, Guerin PM, Ward RD. Identification of oviposition attractants for the sandfly Lutzomyia longipalpis (Diptera: Psychodidae) in volatiles of faeces from vertebrates. Physiol Entomol. 1995;20:23-32.

77. Boufana B. The tergal pheromone gland and antennal sensilla of the sandfly Lutzomyia longipalpis. PhD thesis. UK: University of Liverpool; 1990.

78. Spiegel CN, Jeanbourquin P, Guerin PM, Hooper AM, Claude S, Tabacchi R, et al. (1S,3S,7R)-3-methyl-a-himachalene from the male sandfly Lutzomyia longipalpis (Diptera: Psychodidae) induces neurophysiological responses and attracts both males and females. J Insect Physiol. 2005:51:1366-75.

79. Bray DP, Bandi KK, Brazil RP, Oliveira AG, Hamilton JGC. Synthetic sex pheromone attracts the leishmaniasis vector Lutzomyia longipalpis (Diptera: Psychodidae) to traps in the field. J Med Entomol. 2009;46:428-34.

80. Bray DP, Alves GB, Dorval ME, Brazil RP, Hamilton JG. Synthetic sex pheromone attracts the leishmaniasis vector Lutzomyia longipalpis to experimental chicken sheds treated with insecticide. Parasit Vectors. 2010;3:16. 
81. Jones TM, Balmford A, Quinnell RJ. Adaptive female choice for middle-aged mates in a lekking sandfly. Proc R Soc L B. 2000;267:681-6.

82. Bray DP, Hamilton JGC. Courtship behaviour in the sandfly Lutzomyia longipalpis, the New World vector of visceral leishmaniasis. Med Vet Entomol. 2007;21:332-8.

83. Spiegel CN, Batista-Pereira LG, Bretas JAC, Eiras AE, Hooper AM, Peixoto AA, et al. Pheromone gland development and pheromone production in Lutzomyia longipalpis (Diptera: Psychodidae: Phlebotominae). J Med Entomol. 2011;48:489-95.

84. Jones TM, Quinnell RJ, Balmford A. Fisherian flies: benefits of female choice in a lekking sandfly. Proc R Soc L B. 1998;265:1651-7.

85. Kather R, Martin SJ. Cuticular hydrocarbon profiles as a taxonomic tool: advantages, limitations and technical aspects. Physiol Entomol. 2012;37:25-32.

86. Chung H, Carroll SB. Wax, sex and the origin of species: dual roles of insect cuticular hydrocarbons in adaptation and mating. Bioessays. 2015;37:822-30.

87. Ingleby FC. Insect cuticular hydrocarbons as dynamic traits in sexual communication. Insects. 2015;6:732-42.

88. Andrade A. Ecologia química de flebotomíneos (Diptera: Psychodidae: Phlebotominae): desenvolvimento de uma armadilha e análise dos hidrocarbonetos cuticulares das espécies. PhD thesis. Brazil: Universidade Federal de Minas Gerais; 2010.

89. Mahamat $H$, Hassanali A. Cuticular hydrocarbon composition analysis for taxonomic differentiation of phlebotomine sandfly species (Diptera: Psychodidae) in Kenya. J Med Entomol. 1998;35:778-81.

90. Kamhawi S, Molyneux DH, Killick-Kendrick R, Milligan PJ, Phillips A, Wilkes TJ, et al. Two populations of Phlebotomus ariasi in the Cévennes focus of leishmaniasis in the south of France revealed by analysis of cuticularhydrocarbons. Acta Trop. 1990;47:145-9.

91. Ryan L, Phillips A, Milligan P, Lainson R, Molyneux DH, Shaw JJ. Separation of female Psychodopygus wellcomei and P. complexus (Diptera: Psychodidae) by cuticular hydrocarbon analysis. Acta Trop. 1986;43:85-9.

92. Phillips A, Milligan PJ, Maroli M, Lane RP, Kamhawi S, Broomfield G, et al. Intraspecific variation in the cuticular hydrocarbons of the sandfly Phlebotomus perfiliewi from Italy. Med Vet Entomol. 1990;4:451-7.

93. Phillips A, Le Pont F, Desjeux P, Broomfield G, Molyneux DH. Separation of Psychodopygus carrerai carrerai and P. yucumensis (Diptera: Psychodidae) by gas chromatography of cuticular hydrocarbons. Acta Trop. 1990;47:145-9.

94. Johansson BG, Jones TM, Widemo F. Cost of pheromone production in a lekking Drosophila. Anim Behav. 2005;69:851-8.

95. González-Caballero N, Rodríguez-Vega A, Dias-Lopes G, Valenzuela JG, Ribeiro JMC, Carvalho PC, et al. Expression of the mevalonate pathway enzymes in the Lutzomyia longipalpis (Diptera: Psychodidae) sex pheromone gland demonstrated by an integrated proteomic approach. J Proteomics. 2014;96:117-32.

96. González-Caballero N, Valenzuela JG, Ribeiro JMC, Cuervo P, Brazil RP. Transcriptome exploration of the sex pheromone gland of Lutzomyia longipalpis (Diptera: Psychodidae: Phlebotominae). Parasit Vectors. 2013;6:56.

97. Rivas GBS, Souza NA, Peixoto AA. Analysis of the activity patterns of two sympatric sandfly siblings of the Lutzomyia longipalpis species complex from Brazil. Med Vet Entomol. 2008;22:288-90.

98. Groot AT, Inglis O, Bowdridge S, Santangelo RG, Blanco C, López JD, et al. Geographic and temporal variation in moth chemical communication. Evolution. 2009;63:1987-2003.

99. Wertheim B. Evolutionary ecology of communication signals that induce aggregative behaviour. Oikos. 2005;109:117-24.

100. Dye C, Davies CR, Lainson R. Communication among phlebotomine sandflies: a field study of domesticated Lutzomyia longipalpis populations in Amazonian Brazil. Anim Behav. 1991;42:183-92.

101. Bray DP, Hamilton JGC. Host odor synergizes attraction of virgin female Lutzomyia longipalpis (Diptera: Psychodidae). J Med Entomol. 2007;44:779-87.

102. Landolt PJ. Sex attractant and aggregation pheromones of male phytophagous insects. Am Entomol. 1997;43:12-22.

103. Jones M. A potential cost of monandry in the lekking. J Insect Behav Springer. 2001;14:385-99.

104. Spiegel CN, Bretas JAC, Peixoto AA, Vigoder FM, Bruno RV, Soares MJ. Fine structure of the male reproductive system and reproductive behavior of Lutzomyia longipalpis sandflies (Diptera: Psychodidae: Phlebotominae). PLoS One. 2013;8:e74898.

105. Azevedo RVDM, Dias DBS, Bretas JAC, Mazzoni CJ, Souza NA, Albano RM, et al. The transcriptome of Lutzomyia longipalpis (Diptera: Psychodidae) male reproductive organs. PLoS One. 2012;7:e34495.
106. Chapman T, Liddle LF, Kalb JM, Wolfner MF, Partridge L. Cost of mating in Drosophila melanogaster females is mediated by male accessory gland products. Nature. 1995;373:241-4.

107. Avila FW, Sirot LK, LaFlamme BA, Rubinstein CD, Wolfner MF. Insect seminal fluid proteins: identification and function. Ann Rev Entomol. 2011;56:21-40.

108. Maroli M, Bettini S, Tricoli D, Khoury C, Perrotti E. Studies on mating plug of two sandfly species, Phlebotomus perniciosus and Phlebotomus papatasi (Diptera: Psychodidae). Parassitologia. 1991;33(Suppl):405-11.

109. Valenta D, Killick-Kendrick R, Killick-Kendrick M. Courtship and mating by the sand fly Phlebotomus duboscai, a vector of zoonotic cutaneous leishmaniasis in the Afrotropical region. Med Vet Entomol. 2000;14:207-12.

110. Jung CR, Kim Y. Comparative transcriptome analysis of sex pheromone glands of two sympatric lepidopteran congener species. Genomics. 2014;103:308-15.

111. Groot AT, Ward C, Wang J, Pokrzywa A, O'Brien J, Bennett J, et al. Introgressing pheromone QTL between species: towards an evolutionary understanding of differentiation in sexual communication. J Chem Ecol. 2004;30:2495-514

112. Niehuis O, Buellesbach J, Gibson JD, Pothmann D, Hanner C, Mutti NS, et al. Behavioural and genetic analyses of Nasonia shed light on the evolution of sex pheromones. Nature. 2013:494:345-8.

113. Hamilton JGC, Brazil RP, Campbell-Lendrum D, Davies CR, Kelly DW, Pessoa FAC, et al. Distribution of putative male sex pheromones among Lutzomyia sandflies (Diptera: Psychodidae). Ann Trop Med Parasitol. 2002;96:83-92.

114. Brazil RP, Caballero NN, Hamilton JGC. Identification of the sex pheromone of Lutzomyia longipalpis (Lutz \& Neiva, 1912) (Diptera: Psychodidae) from Asunción, Paraguay. Parasit Vectors. 2009;2:51.

115. Fernández MS, Salomón OD, Cavia R, Perez AA, Acardi SA, Guccione JD. Lutzomyia longipalpis spatial distribution and association with environmental variables in an urban focus of visceral leishmaniasis, Misiones, Argentina. Acta Trop. 2010;114:81-7.

116. Arrivillaga JC, Feliciangeli MD. Lutzomyia pseudolongipalpis: the first new species within the longipalpis (Diptera: Psychodidae: Phlebotominae) complex from La Rinconada, Curarigua, Lara State, Venezuela. J Med Entomol. 2001;38:783-90.

117. Salomón OD, Feliciangeli MD, Quintana MG, Afonso MMS, Rangel EF. Lutzomyia longipalpis urbanisation and control. Mem Inst Oswaldo Cruz. 2015;110:831-46.

118. Harhay MO, Olliaro PL, Costa DL, Costa CHN. Urban parasitology: visceral leishmaniasis in Brazil. Trends Parasitol. 2011;27:403-9.

119. de Oliveira EF, Silva EA, Casaril AE, Fernandes CE, Paranhos Filho AC, Gamarra RM, et al. Behavioral aspects of Lutzomyia longipalpis (Diptera: Psychodidae) in urban area endemic for visceral leishmaniasis. J Med Entomol. 2013;50:277-84.

120. Alexander B. Dispersal of phlebotomine sandfies (Diptera: Psychodidae) in a Colombian coffee plantation. J Med Entomol. 1987;24:552-8.

121. Coutinho-Abreu I, Sonoda I, Fonseca J, Melo M, Balbino V, Ramalho-Ortigão M. Lutzomyia longipalpis s.l. In Brazil and the impact of the Sao Francisco river in the speciation of this sand fly vector. Parasit Vectors. 2008;1:37.

122. Galati EAB. Morfologia e taxonomia: morfologia, terminologia de adultos e identificação dos táxons da América. In: Rangel EF, Lainson R, editors. Flebotomíneos do Brasil. Rio de Janeiro: FIOCRUZ; 2003. p. 53-175.

123. Galati EAB. Morfologia e taxonomia: classificação de Phlebotominae. In: Rangel EF, Lainson R, editors. Flebotomíneos do Brasil. Rio de Janeiro: FIOCRUZ; 2003. p. 23-51.

124. Ward RD, Hamilton JGC, Dougherty M, Falcão AL, Feliciangeli MD, Perez JE, et al. Pheromone disseminating structures in tergites of male phlebotomines (Diptera: Psychodidae). Bull Entomol Res. 1993;83:437-45.

125. Galati EAB. Sistemática dos Phlebotominae (Diptera, Psychodidae) das Américas. PhD thesis. Brazil: Universidade de Sao Paulo; 1990.

126. Brazil RP, de Andrade W, dos Santos A, Parente J, Hamilton J. Presença de dois morfotipos de Lutzomyia longipalpis (Diptera: Psychodidae) ocorrendo em simpatria em Porto Nacional, estado do Tocantins. XXI Congr. Bras. Entomol. 2010. p. ID:130-1.

127. Hamilton JG, Ward RD. Gas-chromatographic analysis of Lutzomyia longipalpis tergal pheromone gland extract. Parassitologia. 1991;33(Suppl): 283-9. 